\title{
Modelling $n$-dodecane spray and combustion with the transported probability density function method
}

\author{
Yuanjiang Pei ${ }^{\mathrm{a}, *}$, Evatt R. Hawkes ${ }^{\mathrm{a}, \mathrm{b}}$, Sanghoon Kook ${ }^{\mathrm{b}}$, Graham M. \\ Goldin ${ }^{\mathrm{c}}$, Tianfeng $\mathrm{Lu}^{\mathrm{d}}$ \\ ${ }^{a}$ School of Photovoltaic and Renewable Energy Engineering \\ The University of New South Wales, Sydney, NSW 2052, Australia \\ ${ }^{b}$ School of Mechanical and Manufacturing Engineering \\ The University of New South Wales, Sydney, NSW 2052, Australia \\ ${ }^{c}$ Ansys Inc., Lebanon, New Hampshire, USA \\ ${ }^{d}$ Department of Mechanical Engineering \\ University of Connecticut, Storrs, CT 06269-3139, USA
}

\begin{abstract}
An $n$-dodecane spray in temperature and pressure conditions typical of diesel engines, known as Spray A, is modelled by the transported probability density function (TPDF) method coupled with a time-dependent Reynoldsaveraged $k-\epsilon$ turbulence model and a Lagrangian discrete phase model of the liquid spray. To establish a baseline for comparisons, non-reacting cases are first studied. Good results are obtained for the vapour penetration, the mean and variance of fuel mixture fraction, and velocity profiles, with variations in ambient density and injection pressure. These comparisons are more extensive than previous studies due to new experimental data being available. Reacting cases are then investigated for a number of ambient
\end{abstract}

*Corresponding author, Phone number: +1 (630) 252-5237, Present address: Transportation Technology Research and Development Center, Argonne National Laboratory, Argonne, IL 60439, USA

Email address: ypei@anl.gov (Yuanjiang Pei)

Preprint submitted to Combustion and Flame

December 27, 2014

(C) 2015. This manuscript version is made available under the Elsevier user license

http://www.elsevier.com/open-access/userlicense/1.0/ 
conditions and injection parameters, employing a reduced chemical kinetic model. The chemical mechanism incorporates an $\mathrm{OH}^{*}$ sub-mechanism (Hall and Petersen, Int. J. Chem. Kinet. 38, 2006, pp. 714-724) which enables a direct comparison with experimental measurements of the lift-off length that are based on $\mathrm{OH}^{*}$ chemiluminescence. To assess the importance of interactions between turbulence and chemistry, the results from the PDF model are compared to the measurements and to those from a well-mixed model that ignores turbulent fluctuations. Variations of ambient temperature, ambient oxygen concentration, ambient density, and injection pressure are considered. In all cases the PDF model with the EMST mixing model and $\mathrm{C}_{\phi}=1.5$ shows an excellent agreement with the experimental lift-off length and presents improved results compared with the well-mixed model. Ignition delay is however over-predicted by both the PDF method and wellmixed models. Available shock tube data suggests that this may be due to the chemical kinetic model over-predicting ignition delay at higher pressures. Keywords:

Spray A, Transported Probability Density Function, Engine Combustion Network, diesel, ignition, $n$-dodecane 


\section{Introduction}

To reduce pollutant emissions and improve fuel economy, further improvements of the combustion process in diesel engines are required. Several advanced strategies to achieve these improvements involve changes of the ambient conditions including pressure, oxygen concentration and temperature, changes of the injection parameters such as the number, timing, and pressure of injections, and changes of the in-cylinder flow by altering, for example, swirl or bowl geometry. Computational models of diesel combustion can be a valuable tool to seek improvements in this large design space, especially given the stringent performance constraints imposed by emissions legislation and consumer expectations.

In this context, the predictive capability of a model is obviously important, but the environment of a real engine is not a good starting point for validation since it is difficult to control precisely and measurements are limited. Extensive databases for validation of combustion models are available for canonical atmospheric flames, e.g. the references in Ref. [1]. One good example is from the series of International Workshops on Measurement and Computation of Turbulent Non-premixed Flames (TNF workshops) [2], where jet flames [3-5], piloted jet flames [5-7] and bluff-body flames [8], etc., were extensively studied to serve the purpose of validation of combustion models. However these too are not ideal as the ambient conditions are vastly different from those in a diesel engine. For example, the higher pressures experienced in a diesel engine influence the kinetics significantly, and change the regimes of turbulence-chemistry interactions (TCI) by altering parameters such as the Reynolds and Damköhler numbers. Owing to a large injection 
velocity of the order of $500 \mathrm{~m} / \mathrm{s}$, flames in diesel engines are substantially lifted from the nozzle, typically $200-500 D[9,10]$, where $D$ is the nozzle diameter, which results in more substantial mixing prior to the flame compared with a typical atmospheric pressure laboratory lifted flame where the lifted length is limited to roughly 5-100D. Thus, there is a need to test models in the applicable conditions while retaining a canonical and well controlled experiment in which comprehensive measurements are possible.

Recently, efforts have been made to fill this gap via an international collaboration of national laboratories, universities and industry known as the Engine Combustion Network (ECN) [11]. The ECN provides a collaborative platform for experimentalists and modellers to develop and validate computational models to aid in the design of advanced combustion engines. The main focus to date has been on spray flames in diesel engine conditions. Currently, more than 16 research groups worldwide have been involved in modelling the ECN spray flame datasets with different models in different computational codes. $N$-heptane was considered as the first target for experiments and modelling due to the availability of tractable chemical kinetic models. A comprehensive list of $n$-heptane modelling studies can be referred to Ref. [12]. More recently, a new dataset with fuel of $n$-dodecane, named Spray A, was made available through the ECN to promote coordinated studies of a canonical spray flame in conditions relevant to practical diesel engines. Comprehensive experimental data are available, and parametric variations include variations of ambient temperature, ambient density, ambient oxygen concentration and injection pressure for both non-reacting and reacting conditions.

Modelling studies of Spray A performed to date are summarised in table 
1. Luo et al. [13] developed a 106-species skeletal mechanism for $n$-dodecane and validated against Spray A using unsteady Reynolds-averaged NavierStokes (RANS) in conjunction with a well-mixed model to treat turbulencechemistry interactions. Overall good agreement was obtained for the predictions of ignition delay and lift-off length, however, the sensitivity of liftoff lengths with respect to the ambient temperatures was over-estimated. D'Errico et al. [14] implemented a multiple-flamelet representative interactive flamelet (mRIF) model in conjunction with a RANS solver to study Spray A at different ambient temperature and oxygen conditions. A $\beta$ form was assumed for the scalar PDFs and good agreement was obtained. The results from the mRIF model were also compared to those from a well-mixed model. Significant improvements were found when considering the TCI effect. Kundu et al. [16] used the same mRIF approach to conduct a more comprehensive study of Spray A at different ambient conditions. Different forms of scalar PDFs were also evaluated. The most relevant study for the present work is Bhattacharjee and Haworth et al. [17], who applied a RANS implementation of the transported probability density function (TPDF) approach and compared results using this method to a well-mixed model which ignores turbulence-chemistry interactions. It was reported that the TPDF model gave much better results than the well-mixed model.

Similar to Refs. [12, 17, 20], the present study focuses on modelling diesel spray combustion using the transported probability density function (TPDF) method [21]. The principal advantage of this method is that it treats the source term exactly without approximation. This is expected to provide significant advantages in the modelling of finite rate processes such as ignition 
Table 1: Summary of modelling studies of Spray A.

\begin{tabular}{|c|c|c|c|}
\hline Groups & Formulations & $\begin{array}{l}\text { Chemical mech- } \\
\text { anisms }\end{array}$ & TCI model \\
\hline Luo et al. [13] & URANS & 106-species [13] & Well-mixed \\
\hline $\begin{array}{l}\text { D'Errico et al. }[14 \text {, } \\
15]\end{array}$ & URANS & $\begin{array}{l}\text { 106-species [13], } \\
\text { 88-species, } 104- \\
\text { species }[15]\end{array}$ & $\mathrm{mRIF}$ \\
\hline Kundu et al. [16] & URANS & $\begin{array}{l}\text { 103-species } \quad[18, \\
\text { 19], 106-species } \\
{[13]}\end{array}$ & $\mathrm{mRIF}$ \\
\hline $\begin{array}{l}\text { Bhattacharjee and } \\
\text { Haworth [17] }\end{array}$ & URANS & $\begin{array}{l}\text { 103-species }[18, \\
19]\end{array}$ & Composition PDF \\
\hline $\begin{array}{l}\text { Pei, Hawkes et al., } \\
\text { this work }\end{array}$ & URANS & 88-species & Composition PDF \\
\hline
\end{tabular}

and pollutant formation. Another feature of the model is that it is not specific only to premixed or non-premixed combustion, which is expected to be an advantage considering that diesel combustion is widely agreed to involve both premixed and non-premixed modes [22, 23]. Finally, the TPDF model also makes no assumption about the relative timescales associated with mixing and chemical reaction. This too may prove to be an advantage considering the intense mixing expected near the nozzle where relatively slow, low temperature chemistry is active, and the transition to a fast-chemistry, mixing-controlled mode of combustion downstream. 
Most previous applications of the PDF model have focussed on atmospheric pressure gas-phase laboratory flames, with substantial success [2432]. A few studies have considered multi-phase problems where a Lagrangianparticle-based method was used to treat the spray while the gas-phase was treated with the TPDF approach [33-37]. An excellent review of recent progress in PDF methods can be found in Ref. [38]. However, few works have considered applications of the model in engine-relevant conditions, and thus further work is needed in this direction.

In previous studies $[12,20]$, we modelled an $n$-heptane spray injection and combustion in a constant volume chamber with high pressure and high temperature ambient conditions (spray H). Ref. [20] treated the spray simply by approximating it as a gaseous jet, while Ref. [12] employed a Lagrangian discrete phase spray model. In the latter work, comprehensive evaluations of the mixing model, mixing constants, and chemical mechanisms were conducted. Excellent agreement was obtained for the spray structure in non-reacting cases and for lift-off length and ignition delay in reacting cases, given appropriate choices for mixing constant, mixing model and chemical mechanism. It was also demonstrated that the PDF model significantly improved the predictions compared to a well-mixed model which ignores turbulence-chemistry interactions.

The present work extends the previous study of Spray H ( $n$-heptane) to Spray A ( $n$-dodecane), and is among the first modelling works considering Spray A. The objectives of the present study are to quantify and understand the model performance, determine how this is affected by the mixing model, and evaluate the effects of turbulence-chemistry interactions on the results. 
The latter objective will be achieved by comparing the PDF model results to a well-mixed model which ignores turbulence chemistry interactions. Such an approximation is attractive because of its simplicity and low computational cost, but expected to result in significant errors if turbulent fluctuations are non-negligible. Several previous works [39-50] have demonstrated such approaches are able to predict at least qualitative trends, but systematic comparisons with more advanced (and expensive) approaches number very few.

Apart from considering a different fuel, two other aspects are also new compared with the earlier studies of spray H. First, compared with the $n$ heptane dataset, a wider range of experimental parametric variations about Spray A are available, enabling more comprehensive testing of the model. The data include variations of temperature, oxygen concentration, ambient density, and injection pressure. Additional measurements of velocity are also available in non-reacting cases, where the previous $n$-heptane data only included mixture fraction. Second, an $\mathrm{OH}^{*}$ sub-mechanism is implemented to enable a more direct comparison with the experimental lift-off length which is based on $\mathrm{OH}^{*}$ chemiluminescence, compared with earlier works which have employed either ground state $\mathrm{OH}$ or temperature [12-17, 20, 43-60].

The paper is organised as follows. The experimental and numerical details are described in section 2. Non-reacting cases are reported in section 3, including variations of ambient density and injection pressure, with emphasis on the predictions of the spatial and temporal variations of the mean and variance of the mixture fraction and axial velocity. Reacting cases are then studied in section 4 . The predictions of ignition delay and flame lift-off length 
are extensively investigated for different mixing models and mixing constants in various ambient conditions, and compared to both the experimental results and to a set of results from a well-mixed model. Finally the conclusions are summarised in section 5 .

\section{Methodology}

\subsection{Experimental setup}

The spray combustion experiments have been performed under the framework of the Engine Combustion Network, where multiple institutions have agreed to perform experiments at nominally the same ambient conditions and with nominally the same injector. In the present work, modelling results will be compared against data from two facilities: a constant-volume preburn (CVP) combustion vessel operated at Sandia National Laboratories [61, 62], and a constant-pressure flow (CPF) rig operated at CMT-Motores Térmicos, Universitat Politècnica de València [63, 64]. Comparison of the experimental results between these and several other facilities indicates a good agreement between the data from different facilities $[65,66]$. The experiments considered fuel injection into a high pressure and high temperature ambient environment which is nominally quiescent. The levels of oxygen in the environment can be adjusted in both experimental set-ups. In the constant volume vessel, the target conditions are achieved by first filling the chamber with a combustible gas mixture of acetylene, hydrogen, oxygen and nitrogen at near-homogeneous and diluted mixture conditions, which is then ignited resulting in increased temperature and pressure. This mixture is then allowed to cool over a relatively long period of the order of seconds before 
the target temperature and pressure are reached. In the constant flow vessel, the target conditions are achieved by supplying a compressed and heated mixture of oxygen and nitrogen. In both rigs, liquid fuel is injected into the nearly quiescent ambient environment, and combustion results if the ambient contains sufficient oxygen.

Table 2: Common parameters

\begin{tabular}{ll} 
Fuel density $\left(\mathrm{kg} / \mathrm{m}^{3}\right)$ & 698.31 \\
Injection velocity $(\mathrm{m} / \mathrm{s})$ & $595.3^{a}$ \\
Fuel temperature $(\mathrm{K})$ & 363 \\
Orifice diameter $(\mathrm{mm})$ & 0.09 \\
\hline
\end{tabular}

a Not measured. Computed using nozzle discharge coefficient.

Both rigs used Bosch single-hole injectors which are nominally the same, and are representative of modern common-rail direct-injection diesel injectors. The injector has a single axial hole-nozzle of nominal diameter $0.09 \mathrm{~mm}$ with a min-sac type tip. Further information on the injector can be obtained from Ref. [67].

Experimental parameters common between different cases are listed in Table 2. The baseline non-reacting and reacting ambient conditions of the experiments studied in this paper are listed in Table 3. Table 4 gives the compositions of the major species for the studied oxygen conditions in the pre-burn vessel.

Minor species also exist in the pre-burn vessel, which may potentially in- 
Table 3: Experimental ambient conditions.

\begin{tabular}{|c|c|c|c|c|c|c|}
\hline case & $\begin{array}{l}\mathrm{O}_{2} \\
(\%)\end{array}$ & $\begin{array}{l}\mathrm{T}_{a m b} \\
(\mathrm{~K})\end{array}$ & $\begin{array}{l}\rho_{a m b} \\
\left(\mathrm{~kg} / \mathrm{m}^{3}\right)\end{array}$ & $\begin{array}{l}\mathrm{P}_{a m b} \\
(\mathrm{MPa})\end{array}$ & $\begin{array}{l}\mathrm{P}_{i n j} \\
(\mathrm{MPa})\end{array}$ & Facility \\
\hline 1 & 0 & 900 & 22.8 & 6.05 & 150 & $\mathrm{CVP}$ \\
\hline 2 & 0 & 1100 & 15.2 & 4.96 & 150 & CVP \\
\hline 3 & 0 & 1400 & 7.6 & 3.19 & 150 & $\mathrm{CVP}$ \\
\hline 4 & 0 & 900 & 22.8 & 6.07 & 100 & CVP \\
\hline 5 & 0 & 900 & 22.8 & 6.07 & 50 & CVP \\
\hline 6 & 15 & 900 & 22.8 & 5.94 & 150 & $\mathrm{CVP}, \mathrm{CPF}$ \\
\hline 8 & 15 & 800 & 22.8 & 5.25 & 150 & $\mathrm{CVP}, \mathrm{CPF}$ \\
\hline 9 & 15 & 850 & 22.8 & 5.61 & 150 & $\mathrm{CVP}, \mathrm{CPF}$ \\
\hline 10 & 15 & 1000 & 22.8 & 6.62 & 150 & $\mathrm{CVP}$ \\
\hline 11 & 15 & 1100 & 22.8 & 7.3 & 150 & $\mathrm{CVP}$ \\
\hline 12 & 15 & 900 & 22.8 & 5.94 & 100 & $\mathrm{CPF}$ \\
\hline 13 & 15 & 900 & 22.8 & 5.94 & 50 & $\mathrm{CPF}$ \\
\hline 14 & 13 & 900 & 22.8 & 5.94 & 150 & $\mathrm{CPF}$ \\
\hline 15 & 21 & 900 & 22.8 & 5.94 & 150 & $\mathrm{CPF}$ \\
\hline 16 & 15 & 900 & 15.2 & 4.04 & 150 & $\mathrm{CPF}$ \\
\hline 17 & 15 & 900 & 7.6 & 2.02 & 150 & $\mathrm{CPF}$ \\
\hline
\end{tabular}

fluence ignition. Recent modelling studies of the minor species compositions [68] suggest that the minor species in the pre-burn products have a total volume fraction of less than $0.02 \%$ due to very diluted mixture condition. In Ref. [68], the estimated mole fraction of $\mathrm{OH}$ was 3.8 parts per billion 
(ppb) while the mole fraction of $\mathrm{NO}$ was 11.2 parts per million (ppm). In the constant-flow rig, the gas is composed of only oxygen and nitrogen. The agreement of ignition delays between the constant flow and constant volume rig is very good and within 10\% difference for temperatures across the range of conditions considered herein, with the constant volume pre-burn rig having the shorter ignition delay. The lift-off length agrees even better between the rigs, with less than $4 \%$ difference. Although minor species are not the only possible cause of these differences between the vessels, it is one possible explanation. However, the experimental results suggest that inclusion of minor species would not substantially change the findings of the paper. This point will be revisited later.

Table 4: Experimental ambient conditions for the Sandia CVP facility.

\begin{tabular}{llll}
\hline $\mathrm{O}_{2} \%$ & $\mathrm{~N}_{2} \%$ & $\mathrm{CO}_{2} \%$ & $\mathrm{H}_{2} \mathrm{O} \%$ \\
\hline 21 & 69.33 & 6.11 & 3.56 \\
15 & 75.15 & 6.23 & 3.62 \\
13 & 77.09 & 6.26 & 3.64 \\
0 & 89.71 & 6.52 & 3.77 \\
\hline
\end{tabular}

\subsection{Model and numerical parameters}

TPDF model. The Fluent (version 14.5) commercial package was employed [69]. The implementation of the model is the same as in our previous study of $n$-heptane, hence for full details the reader is referred to our previous paper [12]. Very briefly, a Lagrangian Monte Carlo approach was adopted to solve the PDF transport equation. Notional particles carrying a composition and 
enthalpy [70] were tracked within the computational domain. They chemically reacted and exchanged composition information by a mixing model. The assumption of gradient diffusion was used to treat the unclosed turbulent flux term, which is implemented by incrementing particle positions using a Wiener process. To close the molecular mixing term, three mixing models were adopted and evaluated, namely: interaction by exchange with the mean (IEM) [71], modified Curl (MC) [72] and Euclidean minimum spanning trees (EMST) [73]. A fractional step method [74] was used to advance the particle locations.

To assess the effect of turbulence-chemistry interactions, the TPDF results will be compared to those from a well-mixed model which treats the mean chemical reaction rate simply by evaluating the rate with the mean values of temperature, pressure, and species mass fractions. In this case the particle-based TPDF model was not used and instead transport equations were solved for the mean composition. Gradient diffusion was used to close the scalar fluxes.

Spray model. A standard discrete phase approach [75] was used to model the spray. Parcels of droplets were injected with defined velocity and diameter. The particles were subjected to drag according to a high Mach number law [76] and to turbulent dispersion via a stochastic approach [77]. Evaporation was modelled according to the Frossling model [78], while the Ranz-Marshall approach [79] was used for heat transfer.

For the Spray A conditions, the region close to the nozzle that contains liquid droplets terminates well upstream of the flame. The steady state liquid length in Spray A is $10.4 \mathrm{~mm}$ while the minimum flame lift-off length 
is $17.5 \mathrm{~mm}$. Similarly, the transient phase of fuel injection is $0.20 \mathrm{~ms}$ while the minimum ignition delay considered here is $0.32 \mathrm{~ms}$. Thus the spray and main combustion regions do not significantly overlap in time or space. Some simplifications of the spray modelling are therefore reasonable when focusing on the region of the flame. Two simplifications were adopted. The first one was to ignore breakup and collision, with evaporation being the only mechanism of droplet size reduction. Instead, mono-dispersed droplets were injected with an initial droplet diameter that was tuned to lead to approximately correct liquid lengths in the baseline Spray A condition. The initial droplet diameters were kept fixed for the parametric variations about the Spray A baseline. Second, the coupling of the liquid and gas phases was simplified by considering interactions only in the mean. That is, the gas phase source term for evaporation is distributed among all notional particles, and similarly, the evaporation and heat transfer rates of droplets are determined by the differences of composition and temperature between the droplets and the mean values in the gas phase. Further discussions on this point are available in our previous study [12] and a recent review paper [80].

Turbulence model and numerical parameters. Table 5 describes the numerical setup. A compressible, pressure-based, transient solver was coupled with the standard Reynolds-averaged $k-\epsilon$ turbulence model. The choice of RANS versus large-eddy simulation was dictated by considerations of computational cost and the expectation that RANS will remain the workhorse modelling approach in industry for some time to come - see Ref. [12] for a more detailed discussion.

The simulations employed the Rhie-Chow [81] discretisation for pressure 
and SIMPLE for pressure-velocity coupling [82]. A first order upwind discretisation of convective terms was used. Further discussion of the methods used is provided in the Fluent manual [69].

Table 5: Numerical conditions.

\begin{tabular}{ll}
\hline Domain & 2D axisymmetric \\
\hline Solver & Transient, pressure based \\
Turbulence model & Standard $k-\epsilon$ model with $\mathrm{C}_{\mu}=0.09, \mathrm{C}_{\epsilon 1}=1.5^{b}$, \\
& $\mathrm{C}_{\epsilon 2}=1.92, \sigma_{k}=1.0, \sigma_{t}=1.3, \sigma_{\phi}=1.1$ \\
Mixing models & $\mathrm{IEM}, \mathrm{MC}$ and EMST \\
ISAT error tolerance & $10^{-5}$ \\
Discretisation & Standard for pressure, SIMPLE for pressure- \\
& velocity coupling, first order upwind on momen- \\
& tum, density, $k$ and $\epsilon$. \\
\hline
\end{tabular}

${ }^{\mathrm{b}} \mathrm{C}_{\epsilon 1}$ was adjusted to fix the round-jet anomaly [83].

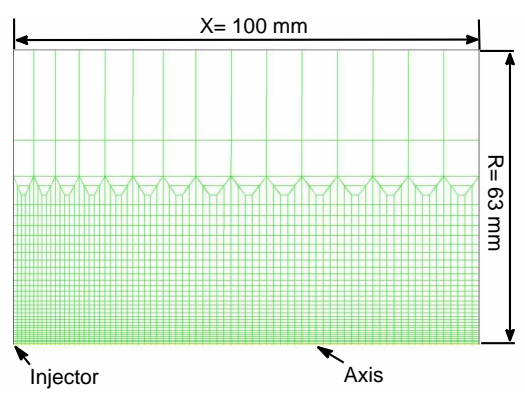

Figure 1: Mesh 2 with 2385 total cells.

A logically unstructured 2-D axisymmetric mesh with dimension of 100 
$\mathrm{mm}$ by $63 \mathrm{~mm}$ (rectilinear in the region with $R<30 \mathrm{~mm}$ ) was adopted, as shown in Fig. 1. It should be emphasized that the maximum axial extent is $X / D=1000$, which is very challenging for modelling as it is much larger than the domains of typical laboratory flames. The initial and boundary conditions are listed in Table 2 and Table 4.

Table 6: Tested meshes

\begin{tabular}{llll}
\hline Mesh & 1 & 2 & 3 \\
\hline Number of cells & 1080 & 2385 & 4200 \\
\hline
\end{tabular}

Extensive convergence studies for both the non-reacting and reacting cases were conducted for a baseline Spray A case with the EMST mixing model and $\mathrm{C}_{\phi}=1.5$. The adequacy of the mesh (as per Table 6), time step size and number of particles per cell $\left(\mathrm{N}_{p c}\right)$, and in reacting cases, the ISAT (In-Situ Adaptive Tabulation, a chemistry acceleration scheme [84]) error tolerance, was assessed. The investigated parameters for the convergence studies in non-reacting cases included vapour penetration and liquid length, radial and axial fuel mass fraction and its variance. In reacting cases, ignition delay and lift-off length were considered. These studies led to the choices of mesh 2 with 2385 cells, 200 notional PDF particles per cell, a time step size $4 \mu \mathrm{s}$, and in reacting cases an ISAT error tolerance of $10^{-5}$. These choices are the same as our previous study of $n$-heptane [12], in which more detailed data justifying the choices can be found. See also Fig. 3 for a typical example. 
Chemical mechanism. Because of the large computational cost of the present TPDF simulations, a reduced chemistry mechanism for $n$-dodecane combustion has been developed. The starting mechanism was a detailed 2115 species mechanism due to Westbrook et al. [18], with some updated rate coefficients as suggested in Sarathy et al. [19]. This was trimmed to a 106 species skeletal mechanism as outlined in Som et al. [13], which was compared therein with the limited available experimental data.

In order to provide a direct comparison with experimental lift-off lengths based on $\mathrm{OH}^{*}$ chemiluminescence, the skeletal mechanism was coupled with a $\mathrm{OH}^{*}$ sub-mechanism from Hall and Petersen [85], including the precursor $\mathrm{CH}$ and related reactions from Ref. [18]. This mechanism was then reduced using quasi-steady state assumptions as outlined in Ref. [86].

The final reduced mechanism is compared at this point in the article with the detailed starting mechanism in Refs. [18, 19]. Figure 2 compares the homogeneous ignition delay of a constant pressure reactor at equivalence ratio $\phi=0.5$ and $\phi=2$. The results were obtained from SENKIN [87]. As may be observed the agreement between reduced and detailed mechanisms is very good. Comparisons with the limited available experimental data will be reported later in section 4.1. The mechanism files are included in the supplementary material to the paper [88].

\section{Non-reacting results}

In this section, non-reacting cases are examined, with variations of ambient density and temperature, and injection pressure. The computational results are compared with the following experimental results: liquid length 


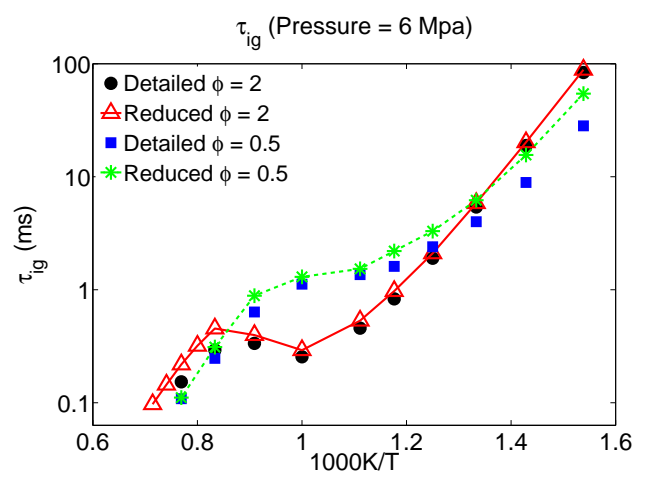

Figure 2: Comparison of predictions of ignition delay between the detailed and reduced chemical mechanisms at $\phi=2$ and 0.5 from a homogeneous constant pressure reactor.

obtained from a threshold criterion on a Mie-scattering signal; vapour penetration obtained from a threshold criterion on a schlieren image; mixture fraction obtained from Rayleigh scattering [62]; and recently available velocity obtained from particle image velocimetry (PIV) [89]. In the computations, the vapour penetration length was defined as the axial distance from the injector to the farthest location of $0.1 \%$ fuel mass fraction. The liquid length was defined as the distance from the injector to the axial location of $0.15 \%$ volume fraction of liquid particles. These definitions are consistent with our previous study of spray $\mathrm{H}[12]$ and ECN recommendations.

\subsection{Baseline case}

Case 1 as listed in Table 3, with ambient density $22.8 \mathrm{~kg} / \mathrm{m}^{3}$, ambient temperature $900 \mathrm{~K}$ and injection pressure $150 \mathrm{MPa}$ is considered as the baseline case. Figure 3 shows the vapour penetration and liquid length versus time for this baseline case. Three different meshes are shown to give one example of a typical convergence study that was performed. It may be 
observed there is little difference between the results on the finest and intermediate meshes, suggesting the intermediate one is sufficient. Moreover, the agreement between experiments and computations is very good for the finer meshes.

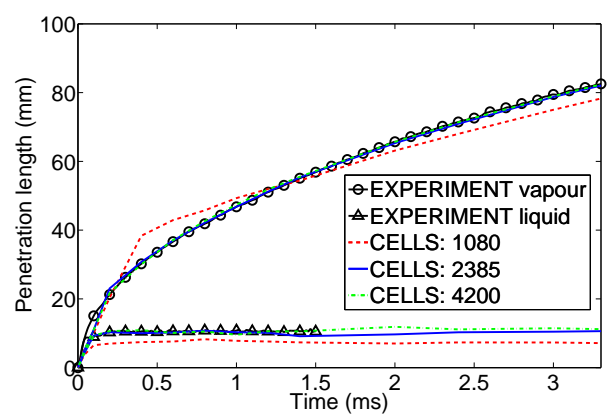

Figure 3: Vapour penetration and liquid length from experiments and computations on different meshes, EMST mixing model with $\mathrm{C}_{\phi}=1.5$. The experimental error of vapour penetration length is within $2 \%$ and liquid length is within $3 \%$.

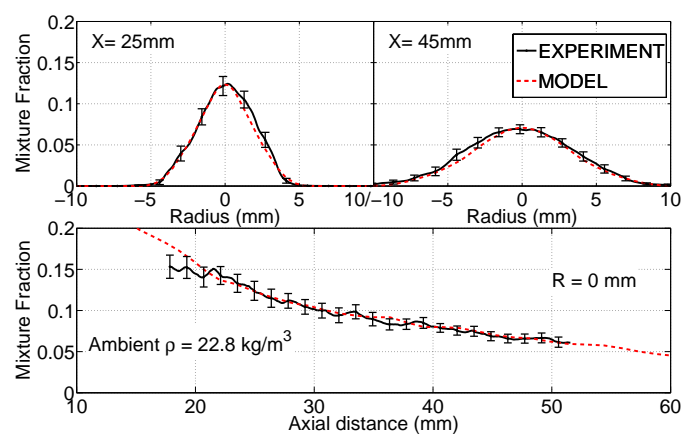

Figure 4: Radial and axial $(\mathrm{R}=0 \mathrm{~mm})$ profiles of fuel mixture fraction from experiments and computations, EMST mixing model with $\mathrm{C}_{\phi}=1.5$. The error bars show the $95 \%$ confidence interval for the experimental data.

Radial profiles of fuel mixture fraction at quasi-steady state were extracted at two axial stations $(25 \mathrm{~mm}$ and $45 \mathrm{~mm})$, while axial profiles were 


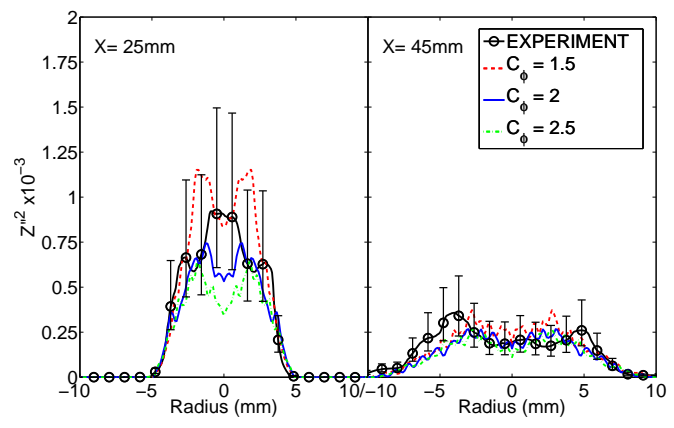

(a) Radial

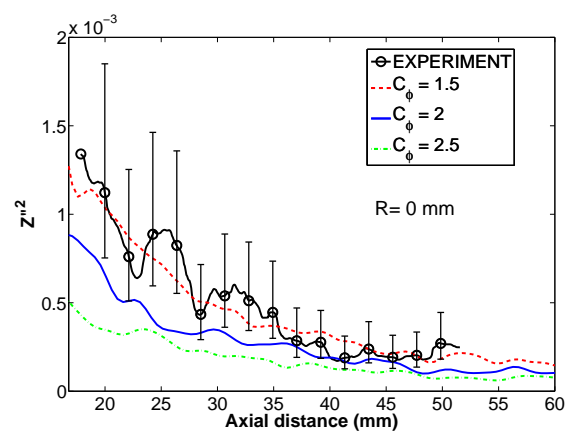

(b) Axial $(\mathrm{R}=0 \mathrm{~mm})$

Figure 5: Radial (a) and axial $(\mathrm{R}=0 \mathrm{~mm}$ ) (b) profiles of fuel mixture-fraction variance from experiments and computations, EMST mixing model with different mixing constants. The error bars show the $95 \%$ confidence interval for the experimental data.

extracted on the jet centreline. These are reported and compared to the experimental results in Fig. 4. Good predictions of the mixture fraction were obtained for both the radial and axial profiles.

Figure 5(a) and Fig. 5(b) report the radial and axial profile of fuel mixturefraction variance from the experiments and computations with the EMST mixing model and different mixing constants $\left(\mathrm{C}_{\phi}\right)$ at the same stations as in Fig. 4. The predicted variance of fuel mixture fraction was directly computed from the instantaneous notional particle data and compared to the experimental variance, which was extracted from the instantaneous Rayleigh scattering images. Both were smoothed by cubic smoothing splines to reduce statistical noise [21]. The smoothing parameter was determined by Reinsch's method [90]. As expected, $\mathrm{C}_{\phi}$ strongly affects the variance. Increasing $\mathrm{C}_{\phi}$ obviously decreases the variance and results in stronger axial decay. As one can see from Fig. 5(b), $\mathrm{C}_{\phi}=1.5$ has a very good match with the experimental 
results and will be used for the rest of the study in this section.

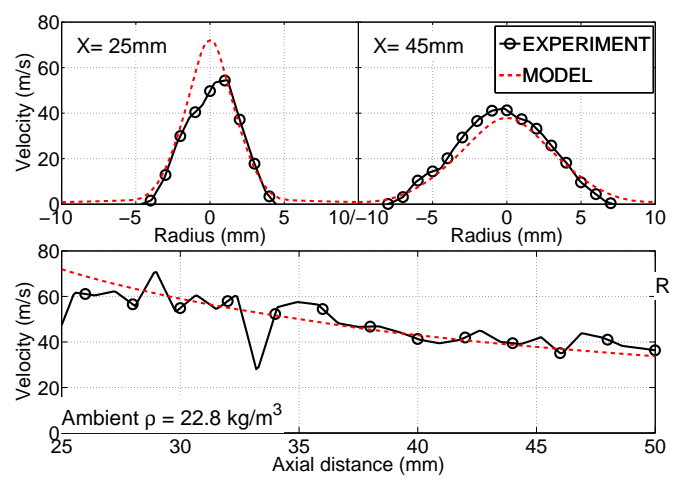

Figure 6: Axial and radial profiles of axial velocity from experiments and computations, EMST mixing model with $\mathrm{C}_{\phi}=1.5$.

In addition to the above comparison, the axial velocity was also examined and is plotted in Fig. 6. The agreement for the radial profiles is excellent except near the middle of the jet at $X=25 \mathrm{~mm}$. At this location, experimental errors are large due to insufficient seeding particle density, as evidenced by the asymmetric profile. In the region of $X=36$ to $50 \mathrm{~mm}$, the agreement with the experiment is also excellent for axial profiles.

The following sections discuss effects of variations of ambient density, temperature, and injection pressure. All computational settings for the baseline case were preserved for these parametric variations.

\subsection{Effect of ambient density and temperature}

Variations of ambient density combined with ambient temperature are examined in this section. The three cases 1-3 are compared with injection pressure held constant at $150 \mathrm{MPa}$, while ambient density was varied. In the experiments, the temperature was simultaneously adjusted with density in 


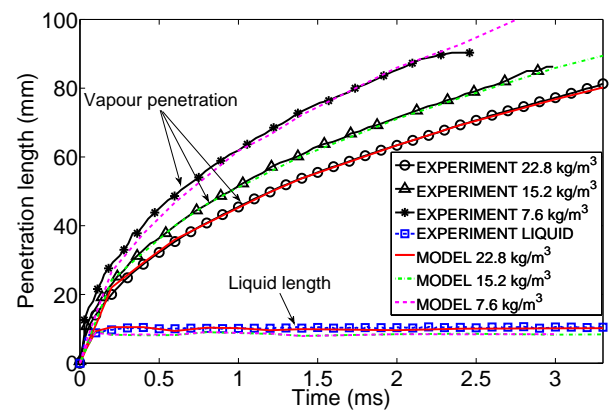

Figure 7: Vapour penetration and liquid length comparison for cases 1 - 3 from experiments and computations, EMST mixing model with $\mathrm{C}_{\phi}=1.5$. The experimental error of vapour penetration length is within $2 \%$ and liquid length is within $3 \%$.

order to result in the same liquid length [62] (temperature was increased as density was decreased).

Figure 7 shows the vapour penetration and liquid length for both experiments and computations at the different ambient conditions. As may be observed, there is no significant difference for the predictions of liquid length between different ambient conditions, as expected. However, the estimates of vapour penetration vary substantially. The modelling recovers this sensitivity well and provides a good match with the experimental results.

The radial and axial profiles of fuel mixture fraction for case 2 are reported in Fig. 8(a) and very good agreement with the measurements may be observed. Figure 8(b) presents the axial velocity profiles for case 2. Similar to case 1 , the modelling results agree very well with experiment, in the region where experimental results are considered accurate. 

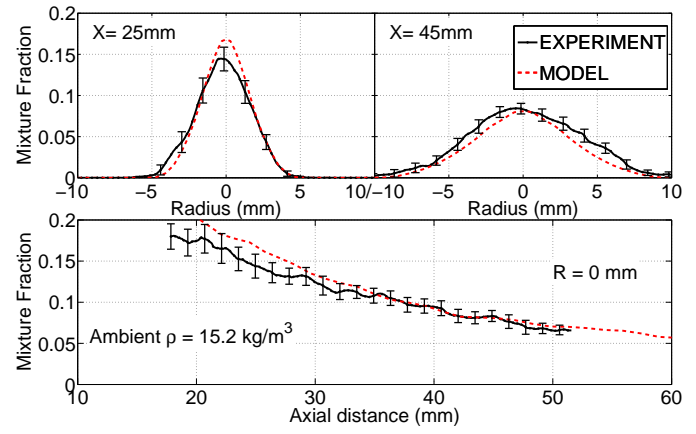

(a) Fuel mixture fraction

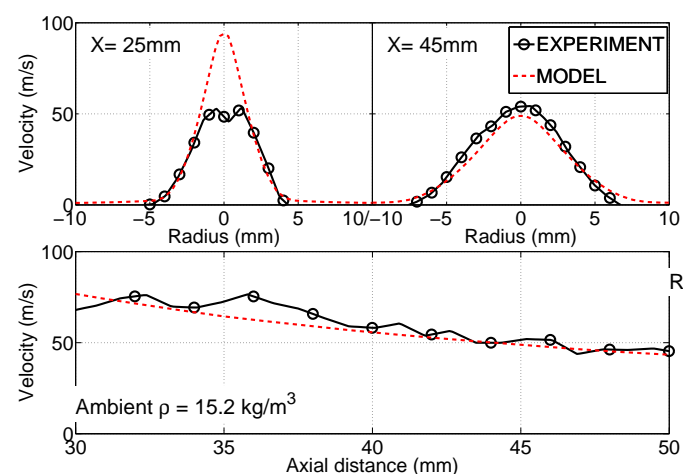

(b) Axial velocity

Figure 8: $\rho_{a m b}=15.2 \mathrm{~kg} / \mathrm{m}^{3}:$ radial and axial $(\mathrm{R}=0 \mathrm{~mm})$ profiles of fuel mixture fraction (a) and axial velocity (b) from experiments and computations, EMST mixing model with $\mathrm{C}_{\phi}=1.5$. The error bars show the $95 \%$ confidence interval for the experimental data.

\subsection{Effect of injection pressure}

In this section the sensitivity to injection pressure is studied. The baseline case 1 with $150 \mathrm{MPa}$, case 4 with $100 \mathrm{MPa}$ and 5 with $50 \mathrm{MPa}$ are considered.

Comparisons of vapour penetration length for these three cases are reported in Fig. 9. As can be seen, lower injection pressure results in shorter vapour penetration length, as expected. The predictions of vapour penetration length for case 4 and case 5 are somewhat low after $1 \mathrm{~ms}$, but the 


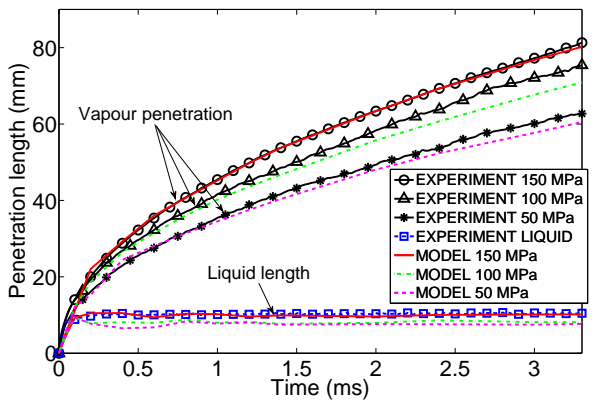

Figure 9: $\mathrm{P}_{i n j}$ variation: vapour penetration and liquid length from experiments and computations, EMST mixing model with $\mathrm{C}_{\phi}=1.5$. The experimental liquid length is for case 1 with $150 \mathrm{MPa}$ injection pressure. The experimental error of vapour penetration length is within $2 \%$ and liquid length is within $3 \%$.

agreement is certainly acceptable and close to being within experimental uncertainty. The experimental liquid length shows an initially surprising feature of being insensitive to injection pressure. It is presumed that at higher pressures, rates of droplet size reduction due to breakup and evaporation are increased, and this nearly cancels with the increased initial droplet momentum. In the modelling, the predictions of liquid length for cases 4 and 5 are shorter than the measurements, however as earlier noted the spray modelling has been simplified as our focus is on the downstream region.

The predicted radial and axial profiles of fuel mixture fraction as compared to the measurements for case 4 and 5 are presented in Fig. 10(a) and Fig. 10(b), respectively. Slight under-predictions can be observed for both cases. However, the overall agreement is good.

The experimental and computational variance for these three cases are shown in Fig. 11. It is shown that the predicted variances are in good agreement with the experiments and no significant differences are observed for 

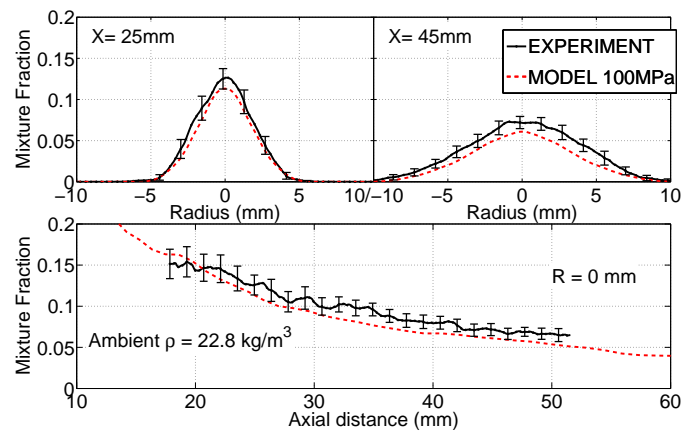

(a) $\mathrm{P}_{i n j}=100 \mathrm{MPa}$
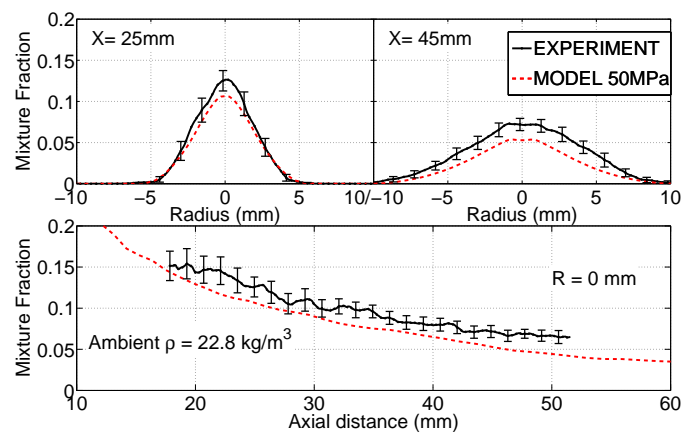

(b) $\mathrm{P}_{i n j}=50 \mathrm{MPa}$

Figure 10: Radial and axial $(\mathrm{R}=0 \mathrm{~mm})$ profile of fuel mixture fraction from experiments and computations at injection pressure $100 \mathrm{MPa}$ (a) and $50 \mathrm{MPa}(\mathrm{b})$, EMST mixing model with $\mathrm{C}_{\phi}=1.5$. The error bars show the $95 \%$ confidence interval for the experimental data.

both experiments and simulations for different injection pressures. As increasing injection pressure essentially amounts to increasing the Reynolds number, and the Reynolds number is high, the observed independence is of course expected once a steady state has been reached.

In conclusion, very good predictions are obtained for mean velocities and mixture fractions in the non-reacting cases compared to the available experimental results covering different ambient conditions. This agreement for the 


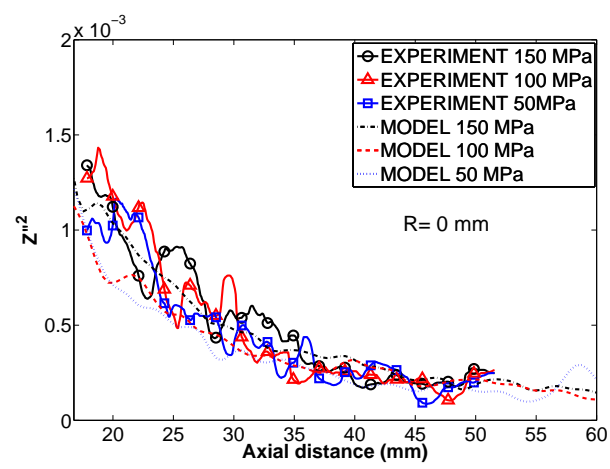

Figure 11: $\mathrm{P}_{i n j}$ variation: axial profile $(\mathrm{R}=0 \mathrm{~mm})$ of fuel mixture-fraction variance from experiments and computations, EMST mixing model with $\mathrm{C}_{\phi}=1.5$.

mean quantities essentially establishes that the turbulence model and numerical approach are performing as expected. Of the quantities compared, the variance is the only one affected by the mixing model, and matching the axial decay of the variance suggests that $\mathrm{C}_{\phi}=1.5$ is the appropriate choice of the mixing constant.

\section{Reacting results}

\subsection{Definitions of the lift-off length and ignition delay}

Experimentally, a line of sight $\mathrm{OH}^{*}$ chemiluminescence signal was used to measure the lift-off length (LOL). As the flame is approached in the axial direction, the experimental images show an initially sharp rise and a local peak, followed by a levelling-off region. The LOL was determined as the location of the signal intensity at $50 \%$ of levelling off value. However, all of the previous modelling studies adopted the ground state $\mathrm{OH}$ or temperature as reference to extract the LOL computationally [12-17, 20, 43-60], and furthermore a point on an axial-radial plane is used as opposed to a line 
of sight. This can possibly be a source of differences between model and experiment. In the present study, since $\mathrm{OH}^{*}$ was available, a more direct comparison was possible.

The model mean $\mathrm{OH}^{*}$ concentration was extracted and then integrated along a line of sight obtained from the distribution of $\mathrm{OH}^{*}$, which is assumed to be axially symmetric. Figure 12(a) shows the obtained planar concentration of $\mathrm{OH}^{*}$ (top), the line of sight integrated values (middle), and the experimental signal (bottom). Figure 12(b) shows the same results but using the ground state $\mathrm{OH}$ in the model. As may be observed, the $\mathrm{OH}^{*}$-based method features a region of high intensity at the lift-off location, which is also observed experimentally and has been referred to as a "lobe" [91]. The peak in the modelling is somewhat stronger than in the experiments however the location and spatial extent is comparable. In contrast the modelled ground state $\mathrm{OH}$ in Fig. 12(b) does not feature a "lobe" region and there is no levelling off: the values tend to keep increasing downstream. Although the present $\mathrm{OH}^{*}$ predictions should be regarded as only qualitative, it is clear that they do present a qualitatively better consistency with the experimental images. It is hoped that this will lead to a better correspondence between measured and modelled definitions of lift-off length.

Ignition delay (IG) was defined as the time from the start of injection to the time where the maximum rate of rise of the maximum Favre-averaged temperature occurs, which has been suggested at the Engine Combustion Network workshops [59, 66]. A comparison of different definitions suggested that the ignition delay results were relatively insensitive to the definition [66]. 


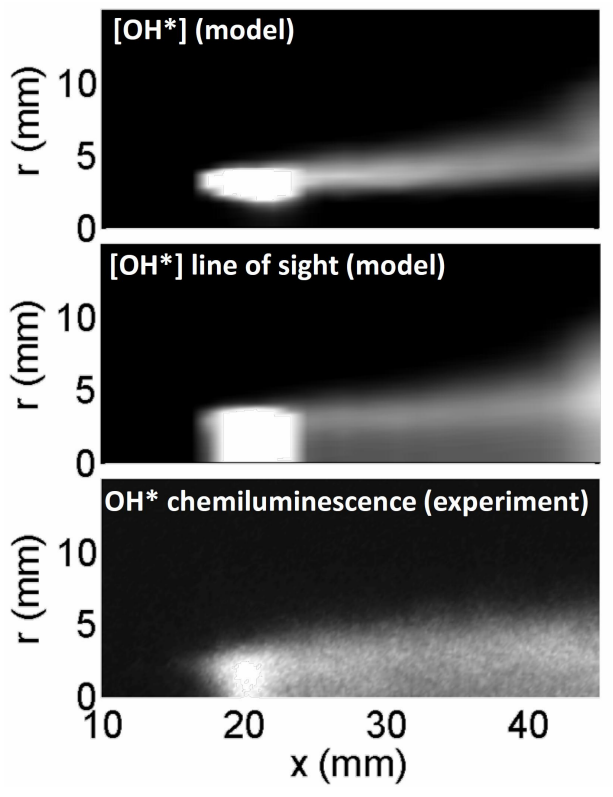

(a) $\mathrm{OH}^{*}$

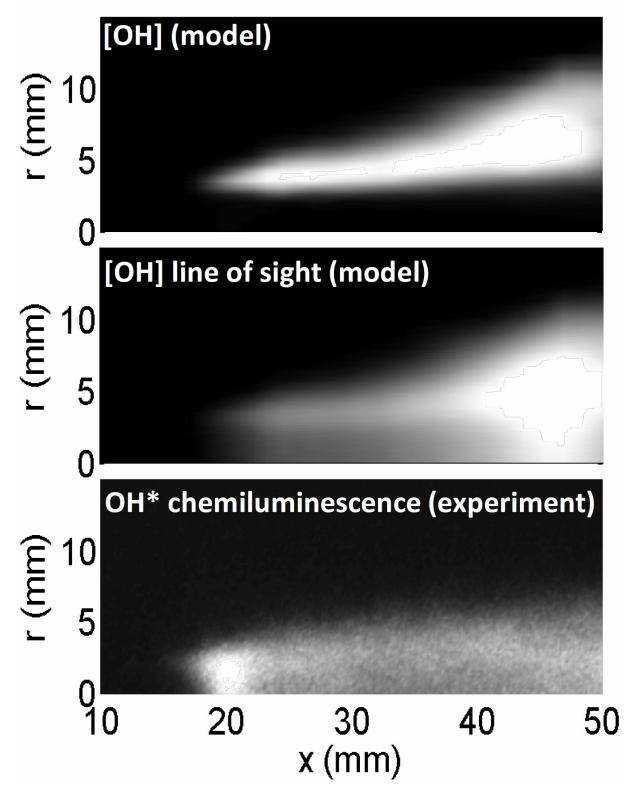

(b) $\mathrm{OH}$

Figure 12: Comparison of $\mathrm{OH}^{*}$ (a) and $\mathrm{OH}$ (b) between computations and experiments under $15 \% \mathrm{O}_{2}, 14.8 \mathrm{~kg} / \mathrm{m}^{3}$ at $4 \mathrm{~ms}$, EMST mixing model.

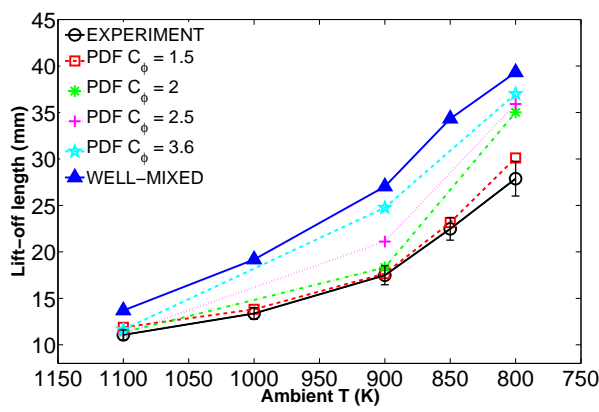

Figure 13: Comparison of lift-off length between experiments and computations from the PDF model with different $\mathrm{C}_{\phi}$ and the well-mixed model at different ambient temperature, the PDF model uses the EMST mixing model. 


\subsection{Ambient temperature variations}

The lift-off length with different $\mathrm{C}_{\phi}$ is compared with experiments as ambient temperature is varied in Fig. 13. For reference, the results with a well-mixed model are also plotted. A four times finer mesh was used for the well-mixed model, which is consistent with what was required in our previous studies of spray $\mathrm{H}[12,20]$. First, one can observe that the predictions with $\mathrm{C}_{\phi}=1.5$ match the measurements very well. This value of $\mathrm{C}_{\phi}$ is in agreement with the earlier non-reacting results considering the mixture-fraction variance, and will be used for further studies later in the paper. Similarly to our previous studies with $n$-heptane $[12,20]$, the lift-off length is observed to be sensitive to $\mathrm{C}_{\phi}$. The earlier study showed that the sensitivity increased with decreasing oxygen concentration, while here it is shown to decrease with increasing ambient temperature. It is probably the case that the sensitivity simply increases with the lift-off length, or equivalently towards less reactive mixture conditions. Arguably, this is due to an increasing level of turbulencechemistry interactions at less reactive conditions, but it may also be simply that the flame response to any perturbation of parameters is relatively more sensitive for less reactive conditions.

Fig. 13 shows that the well-mixed model over-predicts the experimental lift-off length. Comparing the TPDF results with the well-mixed results shows that the TPDF model greatly improves the prediction of the lift-off length, given reasonable choices for the mixing constant. For the larger $\mathrm{C}_{\phi}$ values, the PDF model results approach those from the well-mixed model, as expected in the fast-mixing limit. These findings are consistent with our

earlier studies with $n$-heptane $[12,20]$ and a recent work by Bhattacharjee 
and Haworth et al. [17], thus providing support that the findings are not strongly dependent on the fuel or modelling code being used.

The differences between the well-mixed model and the TPDF model are more pronounced at the less reactive conditions with a longer lift-off length, which again suggests that either TCI are larger at these conditions or that the sensitivities are simply greater. It is worth discussing this point further. If the lift-off location is further downstream, there is certainly more time for the mixture-fraction fields to mix and homogenise prior to the flame, which might lead one to suggest that a well-mixed approximation should improve. Similarly, in the flame itself, chemistry is slower in less reactive conditions, which should also lead to increased homogenisation during combustion. However, the data indicate that the well-mixed approximation deteriorates downstream, which suggests it is the sensitivity that is more pronounced at less reactive conditions, rather than absolute error committed by ignoring turbulent fluctuations. To say this in a more concrete way, it may be that the well-mixed approximation to the mean reaction rate actually improves further downstream, but the sensitivity to errors in the reaction rate are greater, which compound and lead to larger absolute errors in the results.

Ignition delay versus ambient temperature for the TPDF model is shown in Fig. 14. Also shown are the results from the well-mixed model and results from a homogeneous constant pressure reactor. In contrast to the lift-off length, the modelled ignition delay over-predicts the measurements systematically and is not sensitive to $\mathrm{C}_{\phi}$ (not shown here due to the space). The lack of sensitivity to $\mathrm{C}_{\phi}$ has been explained in our previous article [20]. The sensitivity of LOL to $\mathrm{C}_{\phi}$ is higher than that of ignition delay due to the fact 


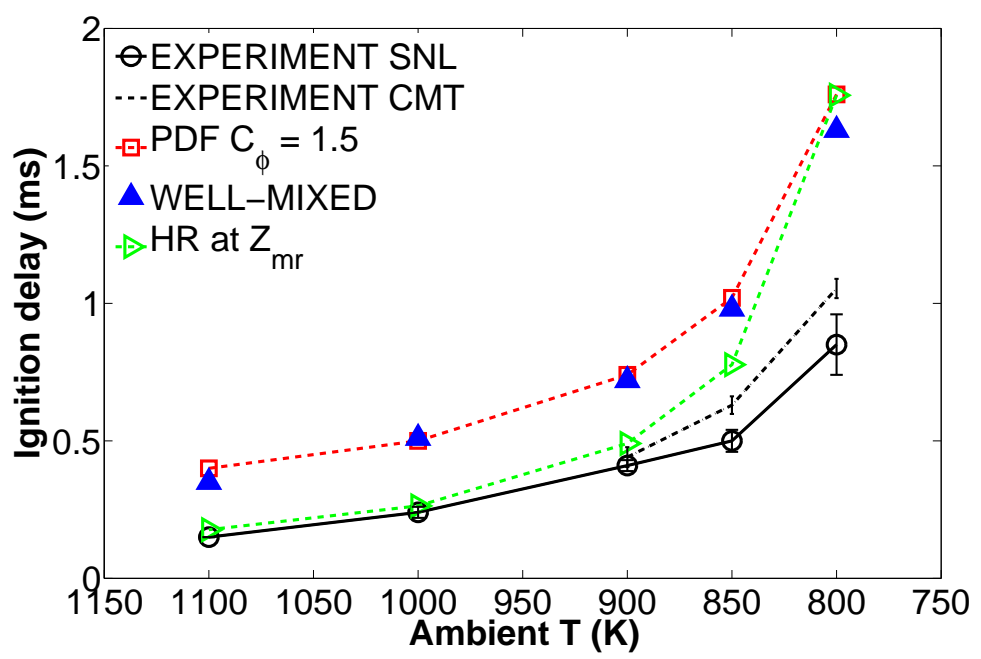

Figure 14: Comparison of ignition delay between experiments and computations from the PDF model with $\mathrm{C}_{\phi}=1.5$, the well-mixed model and a homogeneous reactor at different ambient temperature, the PDF model employs the EMST mixing model.

that the scalar dissipation rate at the upstream and off-jet-axis region where flame stabilises is much higher than the rate where flame ignition happens, which is further downstream and on the jet axis. The TPDF model does not improve the results for ignition delay relative to the well-mixed model. This can also be explained using the above argument.

\subsection{Analysis of ignition delay discrepancy}

The homogeneous constant pressure reactor results were obtained from SENKIN and correspond to the ignition delay of the "most-reactive mixturefraction" $\left(Z_{m r}\right)$, defined as the mixture fraction which has the shortest ignition delay [92], which in the present conditions is on the rich side. The homogeneous reactor results are shorter than the TPDF results, as a result of the finite time in the PDF simulations to form an ignitable mixture, and 
loss of heat and radicals from ignition kernels. However, it is noted that the homogeneous reactors have a longer ignition delay than the experimental measurements towards lower temperature conditions. The homogeneous reactor results could be thought of as a limit case in which a fluid element instantly achieves the state of the most reactive mixture, then subsequently is transported up to the ignition location, without interacting at all with its surrounding environment of less reactive mixtures. As a finite time for evaporation and mixture formation is needed to form an ignitable mixture, and subsequently the very first igniting mixtures will be affected by transport of radicals and heat out of ignition kernels, presumably delaying ignition, it is therefore expected that the homogeneous reactor results would be uniformly shorter than the experimental results (as indeed they are compared with the PDF results). Two possible explanations are offered. First, an obvious candidate is the chemical kinetic model. A second candidate is an issue with the experimental boundary conditions, for example the minor species composition of the pre-burn products.

To evaluate the first possibility, the available experimental data for ignition delay from shock tubes at high pressure conditions has been collated. Data for $n$-dodecane at higher pressure and at richer conditions was unavailable, so it has been complemented by n-decane. Experimental and modelling results for stoichiometric n-alkane ignitions suggest that the ignition delay is not strongly dependent on the size of the alkane [18]. At rich mixtures, modelling suggests that differences may become more pronounced in the negative temperature coefficient (NTC) region, but the differences between dodecane and decane according to the model are still small [19]. Figure 15 
shows shock tube and modelling ${ }^{1}$ results for $\phi=0.5,1$, and 2 , at various pressures, collated from Pfahl et al. [93], Zhukov et al. [94], and Vasu et al. [95]. In some temperature conditions the agreement is quite good towards the lower ambient pressures, however the available data suggest a trend of over-prediction towards higher pressures. The trends are consistent with the PDF results which over-predict ignition delay at $6 \mathrm{MPa}$. Note that the previously shown result in Fig. 2 demonstrated that the reduced and detailed mechanisms agreed, suggesting that further work on the detailed starting mechanism may be beneficial for future studies of Spray A.

Regarding the second possibility to explain differences between model and experiment, constant pressure homogeneous reactor calculations have been performed with the skeletal mechanism in Ref. [13] (from which the present reduced mechanism was derived) with small amounts of $\mathrm{OH}$ and $\mathrm{NO}$ in the initial mixture, as these are the species likely to affect ignition. Another modelling study [68] has suggested that $\mathrm{OH}$ levels are in the order of 3.8 ppb, while NO levels are in the order of $11.2 \mathrm{ppm}$ in the Sandia chamber. The runs were therefore performed with conservative estimates of $20 \mathrm{ppb}$ OH and 100 ppm NO. NO chemistry was included from GRI-MECH 3.0 [96]. Figure 16 shows the results as compared to the experimental data and to the modelling data without minor species. It is observed that the minor species do affect ignition, and this effect is significant at the lower ambient temperatures, however the effect is insufficient to explain the difference between the experimental and modelling results for the Sandia pre-burn vessel data.

\footnotetext{
${ }^{1}$ The modelling results all model $n$-dodecane.
} 


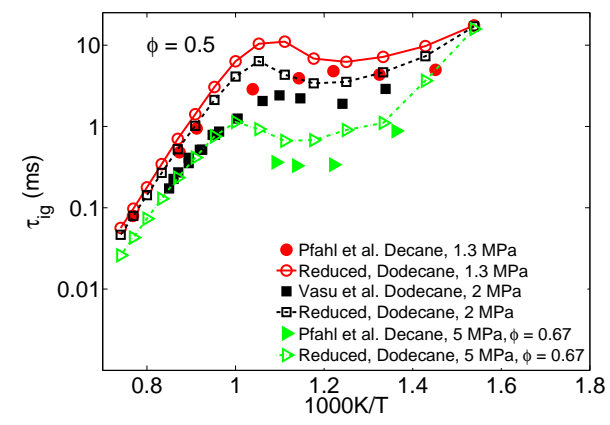

(a) $\phi=0.5$

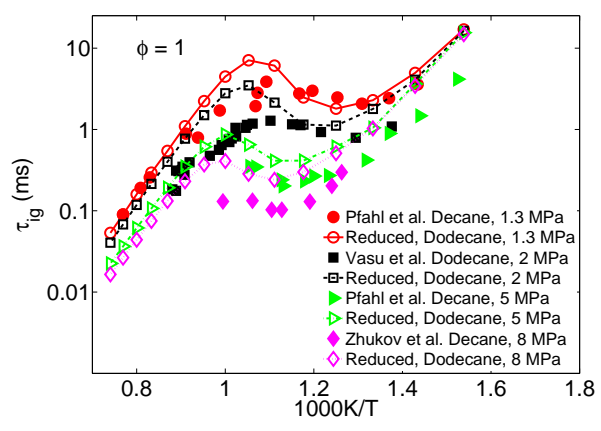

(b) $\phi=1$

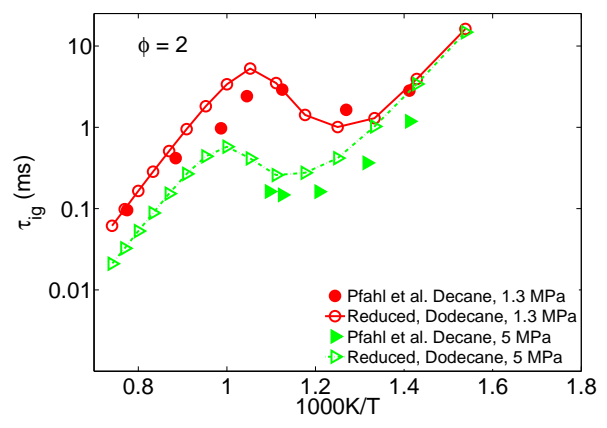

(c) $\phi=2$

Figure 15: Comparison of shock tube experiments and predictions from a constant volume HR at $\phi=0.5$ (a) (unless otherwise stated), $\phi=1$ (b) and $\phi=2$ (c).

Furthermore, referring back to Fig. 14, ignition delays from the constant flow vessel, which does not have any minor species in the ambient gases, are larger than those from the pre-burn vessel, but again the difference is not substantial enough to account for the differences between the model and experiment. The present results do, however, suggest that minor species may be responsible for the observed differences between the different vessels.

Thus, overall the analysis suggests that the reason for the overestimates of the ignition delay is probably traceable to the modelling of the chemical 


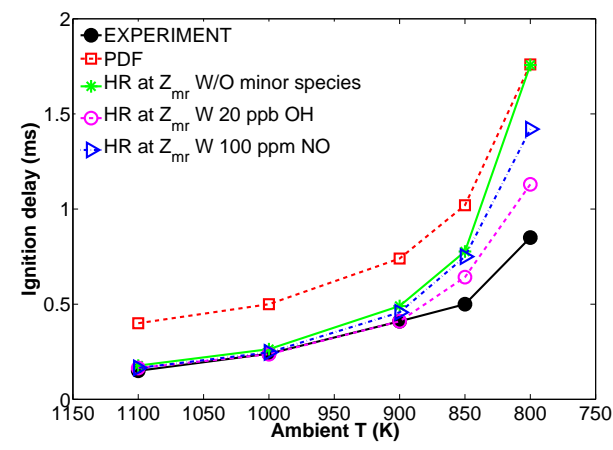

Figure 16: Comparison of the effects of minor species on ignition delay in a homogeneous reactor at different ambient temperature.

kinetics.

\subsection{Mixing model variations}

The effects of the mixing models on ignition delay and lift-off length (with the same $\left.\mathrm{C}_{\phi}=1.5\right)$ are now presented in Fig. 17. It may be noted from Fig. 17(a) that EMST gives excellent predictions of the LOL at different ambient temperature conditions and performs better than the MC and IEM mixing models. Given the observed sensitivity of the lift-off length to $\mathrm{C}_{\phi}$ it would be possible to improve the predictions with MC and IEM by reducing $\mathrm{C}_{\phi}$, but this is not attempted here. The important point is that EMST gives a shorter lift-off length than the other models. This is consistent with what we found in our earlier study of $n$-heptane [12]. The reason for the difference is probably that EMST preserves locality of mixing in composition space. Thus, igniting particles are less likely to mix with non-reacting particles, an event which would presumably delay ignition, and more likely to mix with other igniting particles. Similar effects have been observed contrasting EMST's predictions of extinction and reignition to those of the other models 


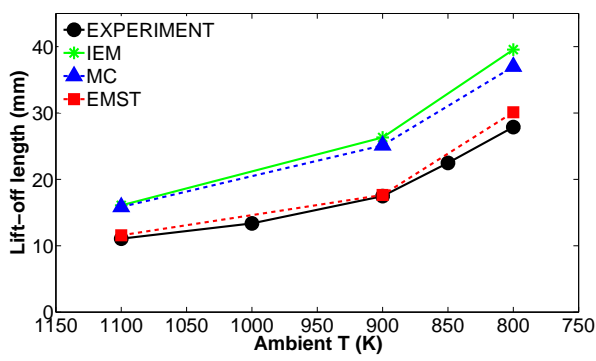

(a) Lift-off length

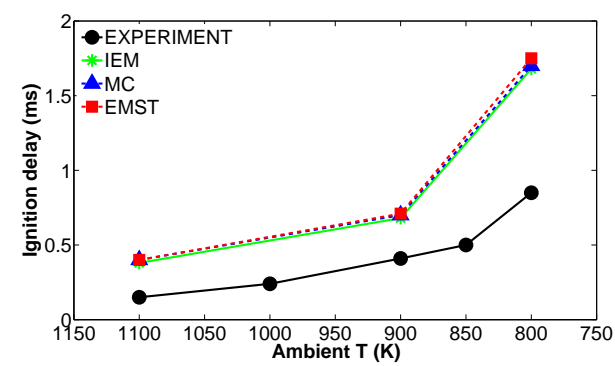

(b) Ignition delay

Figure 17: Comparison of lift-off length (a) and ignition delay (b) from experiments and computations with different mixing models at different ambient temperature, $\mathrm{C}_{\phi}=1.5$.

$[97,98]$. Here, the predictions from MC are slightly better than those from IEM. This is also consistent with our earlier study.

As for the ignition delay, Fig. 17(b) shows little influence of the mixing model, which is consistent with the earlier discussions.

Overall, EMST mixing model with $\mathrm{C}_{\phi}=1.5$ gives best predictions among all the mixing models and this will be used as the baseline setup for further comparisons. 


\subsection{Effect of ambient $\mathrm{O}_{2}$ condition}

The predictions of LOL and ignition delay under variations of ambient $\mathrm{O}_{2}$ are compared to the measurements and to a well-mixed model and reported in Fig. 18.

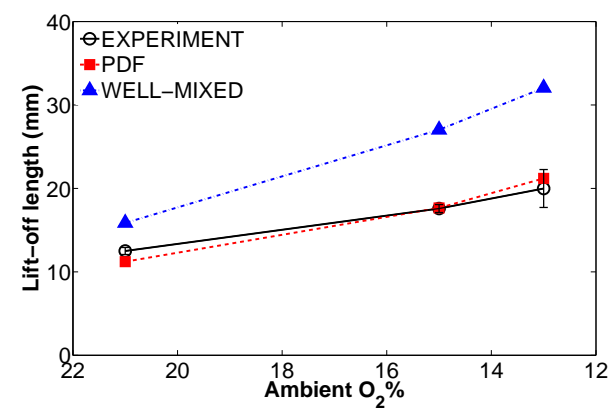

(a) Lift-off length

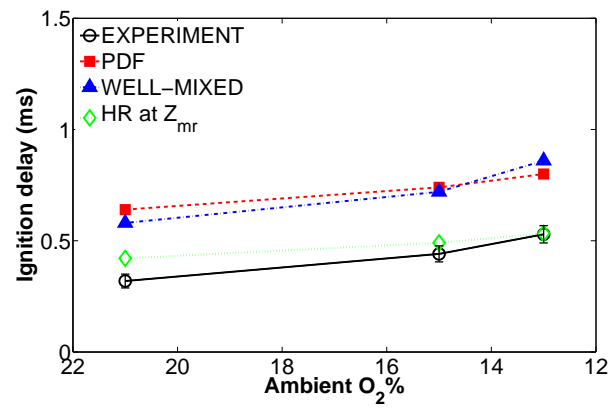

(b) Ignition delay

Figure 18: Comparison of lift-off length (a) and ignition delay (b) from experiments and computations (PDF, well-mixed models and $\mathrm{HR}$ ) at different ambient $\mathrm{O}_{2}$ conditions, EMST mixing model with $\mathrm{C}_{\phi}=1.5$.

Once again the predicted LOL is improved for the TPDF method compared with the well-mixed model, and the quantitative agreement is very good for the former. The sensitivity to oxygen is over-predicted by the well- 
mixed model, consistent with the observations for temperature.

For the ignition delay shown in Fig. 18(b), both models over-predict the experiments, although the sensitivity appears to match well, unlike for temperature where the sensitivity appears to be overestimated.

\subsection{Injection pressure variations}

Injection pressure influences the parameter space of turbulence-chemistry interactions through its effect on the turbulence and mixture formation. With a fixed chemical timescale, higher injection pressure will increase velocity and thus causes the Reynolds number to increase, the Damköhler number to decrease, and the Karlovitz number to increase. It also affects mixture formation in that higher pressure leads to faster break-up, evaporation, and more intense mixing, leading to a more rapid formation of ignitable mixture.

The predictions of LOL and ignition delay with different injection pressures are compared to the measurements in Fig. 19.

The PDF and well-mixed models both capture the experimental trend of the LOL in that higher injection pressure results in longer lift-off length as shown in Fig. 19(a). The increasing lift-off length with pressure probably results from increased velocity, leading to fluid elements moving further downstream before they ignite. A lower Damköhler number may be another secondary factor. The predictions of PDF model are improved relative to the well-mixed model, which systematically over-predicts the experiments. However in contrast to the results for ambient temperature variations, the sensitivity to injection pressure is roughly correct for the well-mixed model.

Figure 19(b) reports the ignition delay predictions compared to the measurements. Both the PDF and well-mixed models once again over-estimate 


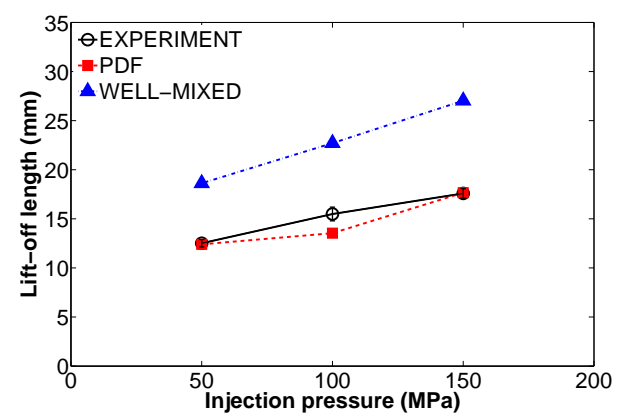

(a) Lift-off length

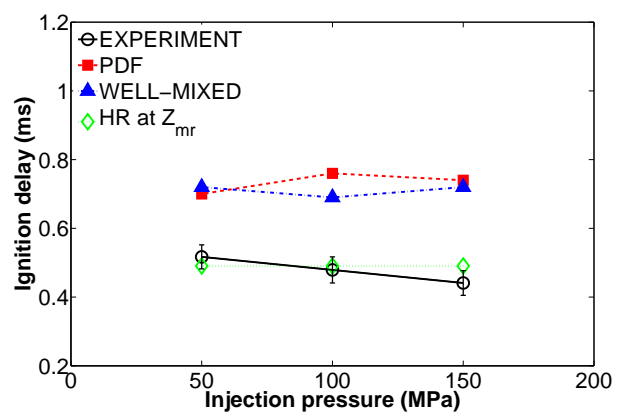

(b) Ignition delay

Figure 19: Comparison of lift-off length (a) and ignition delay (b) from experiments and computations (PDF and well-mixed models) at different injection pressure, EMST mixing model with $\mathrm{C}_{\phi}=1.5$.

the measurements. Neither model correctly predicts the sensitivity. The experimental results suggest a weak but clear decrease of ignition delay with pressure. This presumably results from faster mixture formation, as the lower Damköhler number associated with higher pressure would presumably result in the opposite trend. This has been discussed in Ref. [99]. 


\subsection{Effect of ambient density / pressure}

Finally, ambient density and pressure variations were also studied in the constant flow vessel. (Increasing the density at fixed temperature obviously requires a corresponding pressure increase.) Figure 20 shows the predictions of LOL and ignition delay as ambient density (and pressure) is varied.

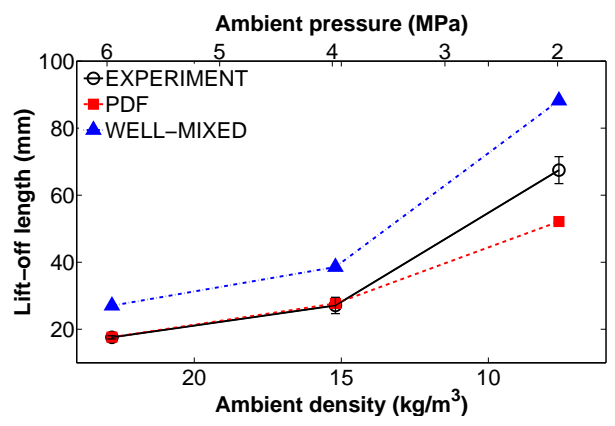

(a) Lift-off length

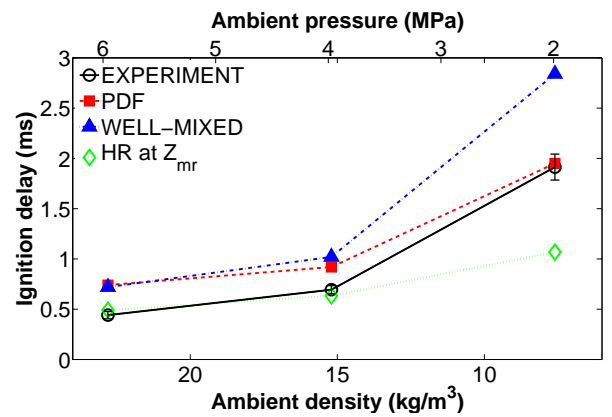

(b) Ignition delay

Figure 20: Comparison of lift-off length (a) and ignition delay (b) from experiments and computations (PDF, well-mixed models and HR) at different ambient density conditions, EMST mixing model with $\mathrm{C}_{\phi}=1.5$.

The predicted LOL for the TPDF model at the higher ambient density conditions (22.8 and $15.2 \mathrm{~kg} / \mathrm{m}^{3}$ ) are excellent compared to the measure- 
ments, while at the lower ambient density $\left(7.6 \mathrm{~kg} / \mathrm{m}^{3}\right)$ the LOL is slightly under-predicted. However, the well-mixed model over-predicts the measurements at all conditions.

Figure 20(b) demonstrates that the ignition delay is over-predicted in the higher ambient density cases (22.8 and $15.2 \mathrm{~kg} / \mathrm{m}^{3}$ ), which correspond to pressures of 6 and $4 \mathrm{MPa}$, respectively. Ignition delay is however very well predicted by the TPDF method at the lower ambient density $\left(7.6 \mathrm{~kg} / \mathrm{m}^{3}\right)$, which corresponds to a pressure of $2 \mathrm{MPa}$. Referring back to Fig. 15, the chemical mechanism performed reasonably well at this pressure, but overpredicted the ignition delays at higher pressures. This reinforces the suggestion that the kinetic model is the cause of discrepancies at higher pressures, and suggests that further research to improve the kinetic model in the high pressure regime may be needed.

\section{Conclusions}

An $n$-dodecane spray flame known as Spray A, a target flame of the Engine Combustion Network, has been modelled. The discrete phase was solved by a standard Lagrangian discrete phase model while the gas phase was treated by the transported probability density function approach.

Non-reacting evaporating sprays were first modelled. Excellent agreement was observed for the vapour penetration, mean mixture fraction, mean axial velocity, and mixture fraction variance, as ambient density and injection pressure were varied. Predictions of mixture fraction variance were sensitive to the value of the mixing constant $\mathrm{C}_{\phi}$, as expected, and for the EMST micromixing model, the value 1.5 was found to provide the best agreement 
over the range of conditions considered.

Reacting cases were then studied using a reduced chemical mechanism which included a sub-model for $\mathrm{OH}^{*}$ to facilitate comparison of experimental and modelled flame lift-off lengths. Variations of ambient temperature, ambient oxygen concentration, ambient density and pressure, and injection pressure were considered about the Spray A baseline. To assess the importance of turbulence-chemistry interactions, the results were compared with a well-mixed model which neglects them. Results for ignition delay were also compared with results from a constant pressure homogeneous reactor. The following are the main conclusions from the study.

Concerning the flame lift-off length:

- A line of sight integration of the modelled $\mathrm{OH}^{*}$ concentration results in a qualitatively different flame visualisation compared with ground state $\mathrm{OH}$. The $\mathrm{OH}^{*}$ method features a rapid and distinct initial rise followed by a levelling-off which is qualitatively similar to experiments, encouraging use of modelled $\mathrm{OH}^{*}$ to identify a lift-off length until quantitative experimental reactive species are available.

- Results for the flame lift-off length with the TPDF method using EMST as the mixing model, and with $\mathrm{C}_{\phi}=1.5$ were excellent across the range of conditions considered.

- Consistent with earlier studies of $n$-heptane [12], lift-off length decreases with $\mathrm{C}_{\phi}$, and the sensitivity to $\mathrm{C}_{\phi}$ is higher in less reactive conditions, i.e. conditions of lower temperature and oxygen concentration.

- Compared to a well-mixed model that neglects turbulence-chemistry 
interactions, the TPDF model provides improved results, particularly in less reactive conditions, suggesting finite rate processes have an important influence on the lift-off length. This, and the point above, suggests that the sensitivity to turbulence-chemistry interactions is larger at less reactive conditions, a finding which concurs with $[12,14,17,20]$. This may be important for the selection of models applicable to lowtemperature combustion engines.

- With the mixing constant chosen to obtain the correct scalar variance decay in non-reacting conditions, EMST provides improved results in reacting cases compared with IEM and MC mixing models, with the other two over-predicting lift-off length. This result however should not be over-interpreted since it would be possible to achieve a good match with IEM or MC by adjusting the mixing constant, which would have the result that the predictions of mixture fraction variance would be deteriorated. Similar trade-offs are noted in studies of other flames, for example Refs. [27, 28] who studied these three mixing models on a piloted jet diffusion flame and a turbulent nonpremixed bluff body flames, respectively, and recent work comparing DNS and TPDF models $[100]$.

Concerning the ignition delay:

- In contrast to the lift-off length, the ignition delay was found to be insensitive to the mixing constant and mixing model, confirming a finding in earlier studies of $n$-heptane [20].

- The TPDF did not improve results for ignition delay compared to the 
well-mixed model except in one low ambient pressure condition.

- At higher ambient pressures of 6 and $4 \mathrm{MPa}$, the TPDF and wellmixed models uniformly over-predicted the ignition delay. Only at a lower ambient pressure of $2 \mathrm{MPa}$ were predictions of ignition delay very good.

- The ignition delay of a homogeneous constant pressure reactor was found to be longer than the experimental ignition delay, which suggested that the chemical kinetic model may be the reason for the discrepancy. Comparison of higher pressure shock tube results for $n$ dodecane and n-decane with the detailed starting mechanism used in this work suggested that indeed ignition delays are over-predicted at higher pressures.

Future work is suggested along the following lines:

- To enable further advances in modelling Spray A, improved chemical kinetic models may be required, the validation of which will require additional experimental data in the conditions relevant to Spray A, for example using shock tubes and/or flow-reactors. Data in high pressures, rich conditions and conditions with EGR are notably lacking.

- Additional experimental data which is more detailed and can be compared more directly with modelling data would be useful. This may include quantitative measurements of temperature, ground state $\mathrm{OH}$, etc., which would be useful to appreciate in more detail the differences between alternative modelling approaches: for example, EMST, IEM 
and the well mixed model give qualitatively different flame structures, even if lifted lengths are similar; but at present it is impossible to know for certain which is more correct.

- TPDF modelling is still computationally expensive. Fruitful avenues for cost reductions include dimensional reduction of chemistry and methods for reducing the particle number.

- Many closure issues associated with introducing additional physics such as sprays, radiation and soot formation have the potential to be dealt with naturally using the TPDF method [38, 80]. Pursuing demonstrations in these areas should be fruitful. For example, improvements of the spray-PDF coupling may enable improved predictions closer to the fuel nozzle.

\section{Acknowledgments}

Y. Pei acknowledges the support of AusAID via its Australian Leadership Awards program. The work was supported by the Australian Research Council and benefited from resources of the National Computational Infrastructure, Australia, Intersect Australia Ltd, and the Leonardi research cluster of the Faculty of Engineering, The University of New South Wales. The work at the University of Connecticut was supported by the U.S. Department of Energy under Grant DE-SC0008622. The authors thank Lyle Pickett and Gilles Bruneaux for their leadership in establishing the Engine Combustion

Network, and Dan Haworth for several useful discussions. Michele Bardi and Raul Payri are thanked for making available their experimental data prior to 
formal publication.

\section{References}

[1] R.S. Barlow, Proc. Combust. Inst. 31 (2007) 49-75.

[2] TNF Workshop web site, available at http://www.ca.sandia.gov/TNF/abstract.html, Sandia National Laboratories, 2014.

[3] R.S. Barlow, G.J. Fiechtner, C.D. Carter, J.-Y. Chen, Combust. Flame 120 (2000) 549-569.

[4] W. Meier, R.S. Barlow, Y.-L. Chen, J.-Y. Chen, Combust. Flame 123 (2000) 326-343.

[5] C. Schneider, A. Dreizler, J. Janicka, E.P. Hassel, Combust. Flame 135 (2003) 185-190.

[6] R.S. Barlow, A.N. Karpetis, Proc. Combust. Inst. 30 (2005) 673-680.

[7] J.H. Frank, S.A. Kaiser, M.B. Long, Proc. Combust. Inst. 29 (2002) $2687-2694$.

[8] B.B. Dally, A.R. Masri, R.S. Barlow, G.J. Fiechtner, Combust. Flame 132 (2003) 272-274.

[9] C.A. Idicheria, L.M. Pickett, Proc. Combust. Inst. 31 (2) (2007) 29312938.

[10] B. Higgins, D. Siebers, SAE Paper 2001-01-0918, 2001. 
[11] Pickett, L.M. et al., Engine Combustion Network data archive, available at http://www.sandia.gov/ecn/index.php (2013).

[12] Y. Pei, E.R. Hawkes, S. Kook, Flow, Turb. Combust. 91 (2013) 249-280.

[13] Z. Luo, S. Som, S.M. Sarathy, M. Plomer, W.J. Pitz, D.E. Longman, T. Lu, Combust. Theory Modell. 18 (2) (2014) 187-203.

[14] G. D'Errico, T. Lucchini, F. Contino, M. Jangi, X-S. Bai, Combust. theory Modell. 18 (1) (2014) 65-88.

[15] G. D'Errico, T. Lucchini, A. Stagni, A. Frassoldati, T. Faravelli, E. Ranzi, SAE Paper 2013-24-0014, 2013.

[16] P. Kundu, Y. Pei, S. Som, M. Wang, R. Mandhapati, Atom. Sprays 24 (9) (2014) 779-800.

[17] S. Bhattacharjee, D.C. Haworth, Combust. Flame 160 (10) (2013) 20832102.

[18] C.K. Westbrook, W.J. Pitz, O. Herbinet, H.J. Curran, E.J. Silke, Combust. Flame 156 (1) (2009) 181-199.

[19] S.M. Sarathy, C.K. Westbrook, M. Mehl, W.J. Pitz, C. Togbe, P. Dagaut, H. Wang, M.A. Oehlschlaeger, U. Niemann, K. Seshadri, and others, Combust. Flame 158 (12) (2011) 2338-2357.

[20] Y. Pei, E.R. Hawkes, S. Kook, Proc. Combust. Inst. 34 (2013) 30393047.

[21] S.B. Pope, Prog. Energy Combust. Sci. 11 (2) (1985) 119-192. 
[22] J. E. Dec, SAE Trans. 106 970873, (1997).

[23] J.E. Dec, Proc. Combust. Inst. 32 (2009) 2727-2742.

[24] R. Cabra, T. Myhrvold, J.Y. Chen, R.W. Dibble, A.N. Karpetis, R.S. Barlow, Proc. Combust. Inst. 29 (2002) 1881-1888.

[25] R.R. Cao, H. Wang, S.B. Pope, Proc. Combust. Inst. 31 (2007) 15431550.

[26] J. Xu, S.B. Pope, Combust. Flame 123 (3) (2000) 281-307.

[27] B. Merci, D. Roekaerts, B. Naud, Combust. Flame 144 (2006) 476-493.

[28] B. Merci, D. Roekaerts, B. Naud, S. B. Pope, Combust. Flame 146 (2006) 109-130.

[29] R.R. Cao, S.B. Pope, A.R. Masri, Combust. Flame 142 (4) (2005) 438453.

[30] V. Raman, H. Pitsch, R.O. Fox, Combust. Flame 143 (2005) 56-78.

[31] Y. Ge, M.J. Cleary, A.Y. Klimenko, Proc. Combust. Inst. 33 (2011) 1401-1409.

[32] A.R. Masri, R. Cao, S.B. Pope, G.M. Goldin, Combust. Theory Modell. 8 (1) (2003) 1-22.

[33] E.H. Kung, D.C. Haworth, SAE Int J Engines 1 (2008) 591-606.

[34] Y.Z. Zhang, E.H. Kung, D.C. Haworth, Proc. Combust. Inst. 30 (2005) 2763-2771. 
[35] S. James, M.S. Anand, S.B. Pope, AIAA Paper 2002-4017, 2002.

[36] H.W. Ge, E. Gutheil, Combust. Flame 153 (2008) 173-185.

[37] R.M. Humza, Y. Hu, E. Gutheil, Experiments and Numerical Simulations of Turbulent Combustion of Diluted Sprays 19 (2014) 129-153.

[38] D.C. Haworth, Prog. Energy Combust. Sci. 36 (2010) 168-259.

[39] P.K. Senecal, E. Pomraning, K.J. Richards, T.E. Briggs, C.Y. Choi, R.M. McDavid, M.A. Patterson, SAE Trans. 112 (3) (2003) 1331-1351.

[40] S. Singh, R.D. Reitz, M.P.B. Musculus, SAE Paper 2006-01-0055, (2006).

[41] G. D'Errico, D. Ettorre, T. Lucchini, SAE Paper 2007-24-0045, (2007).

[42] L.K. Liang, C. Song, C. Jung, R.D. Reitz, J. Eng. Gas Turb. Power 129 (3) (2007) 702-707.

[43] S. Som, S.K. Aggarwal, Combust. Flame 157 (6) (2010) 1179-1193.

[44] G. D'Errico, D. Ettorre, T. Lucchini, SAE Paper 2008-01-0954, 2008.

[45] T. Lucchini, G. D'Errico, D. Ettorre, G. Ferrari, SAE Paper 2009-011971, 2009.

[46] F.P. Kärrholm, F. Tao, N. Nordin, SAE Paper 2008-01-0961, 2008.

[47] T. Lucchini, G. D'Errico, D. Ettorre, Int. J. Heat Fluid Fl. 32 (2011) 285-297. 
[48] G. Vishwanathan, R.D. Reitz, Combust. Sci. and Tech. 182 (8) (2010) 1050-1082.

[49] R. Novella, A. García, J.M. Pastor, V. Domenech, Math. Comput. Model. 54 (2011) 1706-1719.

[50] G. Vishwanathan, R.D. Reitz, SAE Paper 2008-01-1331, 2008.

[51] U. Azimov, N. Kawahara, E. Tomita, K. Tsuboi, Journal of Thermal Science and Technology 5 (2) (2010) 238-251.

[52] M. Bolla, Y.M. Wright, K. Boulouchos, G. Borghesi, E. Mastorakos, Combust. Sci. Tech. 185 (5) (2012) 766-793.

[53] M. Bolla, T. Gudmundsson, Y.M. Wright, K. Boulouchos, SAE Int. J. Engines 6 (2) (2013) 2013-01-1618.

[54] R. Venugopal, J. Abraham, Combust. Sci. Tech. 179 (12) (2007) 25992618.

[55] G. Borghesi, E. Mastorakos, C.B. Devaud, R.W. Bilger, Combust. Theory Modell. 15 (5) (2011) 725-752.

[56] F. Bottone, A. Kronenburg, D. Gosman, A. Marquis, Flow Turb. Combust. 89 (2012) 651-673.

[57] C. Bekdemir, L.M.T. Somers, L.P.H. de Goey, J. Tillou, C. Angelberger, Proc. Combust. Inst. 34 (2013) 3067-3074.

[58] U. Egüz, S. Ayyapureddi, C. Bekdemir, B. Somers, P. de Goey, Fuel 113 (2013) 228-238. 
[59] E.R. Hawkes, Model comparisons: n-heptane session, Engine Combustion Network workshop one, available at http://www.ca.sandia.gov/ecn/workshop/ECN1.php, 2014.

[60] Engine Combustion Network: ECN2 Proceedings, available at http://www.ca.sandia.gov/ecn/workshop/ECN2.php, 2014.

[61] L.M. Pickett, C.L. Genzale, G. Bruneaux, L. Malbec, L. Hermant, SAE Paper 2010-01-2106, 2010.

[62] L.M. Pickett, J. Manin, C.L. Genzale, D.L. Siebers, M.P.B. Musculus, C.A. Idicheria, SAE Int. J. Engines 4 2011-01-0686 (2011) 764-799.

[63] R. Payri, J.M. García-Oliver, M. Bardi, J. Manin, Applied Therm. Eng. 35 (2012) 185-195.

[64] J. Benajes, R. Payri, M. Bardi, P. Marti, Applied Therm. Eng. 58 (1-2) (2013) 554-563.

[65] M. Bardi, R. Payri, L.M. Malbec, G. Bruneaux, L.M. Pickett, J. Manin, T. Bazyn, C. Genzale, Atom. Sprays 22 (10) (2012) 807-842.

[66] E.R. Hawkes, ECN2: ignition and lift-off session, Engine Combustion Network workshop two, Germany, 2012.

[67] L.M. Pickett, C.L. Genzale, G. Bruneaux, L.M. Malbec, L. Hermant, C. Christiansen, J. Schramm, SAE Int. J. Engines 3 2010-01-2106 (2010) 156-181. 
[68] M. Meijer, B. Somers, J. Johnson, J. Naber, S.Y. Lee, L.M. Malbec, G. Bruneaux, L.M. Pickett, M. Bardi, R. Payri and others, Atom. Sprays 22 (9) (2012) 777-806.

[69] ANSYS: FLUENT 14.5 Theory Guide, ANSYS Inc., Canonsburg, U.S.A., 2011, p. 680.

[70] A.Y. Klimenko, M.J. Cleary, Flow, Turb. Combust. 85 (2010) 567-591.

[71] J. Villermaux, J.C. Devillon, Proc. Second Int. Symp. On Chemical Reaction Engineering, ISCRE, New York, 1972, pp.1-13.

[72] J. Janicka, W. Kolbe, W. Kollmann, J. Non-Equilib. Thermodyn. 4 (1) (1979) 47-66.

[73] S. Subramaniam, S.B. Pope, Combust. Flame 115 (4) (1998) 487-514.

[74] R.R. Cao, S.B. Pope, J. Comput. Phys. 185 (1) (2003) 194-212.

[75] J.K. Dukowicz, J. Comput. Phys. 35 (1980) 229-253.

[76] R. Clift, J.R. Grace, M.E. Weber, Bubbles, Drops and Particles, Technical report, Academic Press (1978).

[77] A.D. Gosman, E. Ioannides, J. Energy 7 (6) (1983) 482-490.

[78] N. Frossling, N.A.C.A. AD-B189 (168) (1956).

[79] W.E. Ranz, W.R. Marshall, Chem. Eng. Prog. 48 (3) (1952) 141-146.

[80] P. Jenny, D. Roekaerts, N. Beishuizen, Prog. Energy Combust. Sci. 38 (6) (2012) 846-887. 
[81] C. M. Rhie, W. L. Chow, AIAA Journal 21 (11) (1983) 1525-1532.

[82] S.V. Patankar, D.B. Spalding, Int. J. of Heat and Mass Transfer 15 (10) (1972) 1787-1806.

[83] J. Janicka, N. Peters, Proc. Combust. Inst. 19 (1982) 367-374.

[84] S.B. Pope, Combust. Theory Modell. 1 (1997) pp. 41-63.

[85] J.M. Hall, E.L. Petersen, Int. J. Chem. Kinet. 38 (2006) 714-724.

[86] T. Lu, C.K. Law, Prog. Energy Combust. Sci. 35 (2) (2009) 192-215.

[87] R.J. Kee, F.M. Rupley, J.A. Miller, M.E. Coltrin, J.F. Grcar, E. Meeks, H.K. Moat, A.E. Lutz, G. Dixon-Lewis, M.D. Smooke, J. Warnatz, G.H. Evans, R.S. Larson, R.E. Mitchell, L.R. Petzold, W.C. Reynolds, M. Caracotsios, W.E. Stewart, P. Glarborg, C. Wang, O. Adigun, CHEMKIN collection, release 3.6. Reaction Design, Inc., ISCRE, San Diego, 2000.

[88] Y. Pei, E.R. Hawkes, S. Kook, G. Goldin, T. Lu, supplementary material, Combust. Flame (2013).

[89] M. Meijer, L-M. Malbec, G. Bruneaux, L.M.T. Somers, $12^{\text {th }}$ Triennial International Conference on Liquid Atomization and Spray Systems, ICLASS, Heidelberg, Germany, September 2-6 (2012).

[90] C.H. Reinsch, Num. Math. 10 (3) (1967) 177-183.

[91] D. Siebers, B. Higgins, SAE Paper 2001-01-0530, 2001. 
[92] E. Mastorakos, T.A. Baritaud, T.J. Poinsot, Combust. Flame 109 (1) (1997) 198-223.

[93] U. Pfahl, K. Fieweger, G. Adomeit, Proc. Combust. Inst. 26 (1) (1996) $781-789$.

[94] V.P. Zhukov, V.A. Sechenov, A.Y. Starikovskii, Combust. Flame, 153 (1) (2008) 130-136.

[95] S.S. Vasu, D.F. Davidson, Z. Hong, V. Vasudevan, R.K. Hanson, Proc. Combust. Inst. 32 (1) (2009) 173-180.

[96] G.P. Smith, D.M. Golden, M. Frenklach, N.W. Moriarty, B. Eiteneer, M. Goldenberg, C.T. Bowman, R.K. Hanson, S. Song, W.C. Gardiner, Jr., V.V. Lissianski, Z. Qin, GRI-Mech 3.0, available at http://www. me. berkeley. edu/gri_mech (2013).

[97] Z. Ren, S.B. Pope, Combust. Flame, 136 (1) (2004) 208-216.

[98] S. Mitarai, J.J. Riley, G. Kosály, Phys. Fluids, 17 047101, (2005).

[99] L.M. Pickett, D.L. Siebers, C.A. Idicheria, SAE Paper 2005-01-3843, 2005.

[100] A. Krisman, J.C.K. Tang, E.R. Hawkes, D.O. Lignell, J.H. Chen, Combust. Flame, 161 (4) (2014) 2085-2106. 